\title{
Migração, mobilidades e as cidades da Amazônia: histórias de Xinguara (PA) ${ }^{1}$
}

\author{
Candice Vidal e Souza \\ Pontifícia Universidade Católica de Minas Gerais, \\ Belo Horizonte, Minas Gerais, Brasil \\ candice.vidal@yahoo.com.br
}

Arlete Francisca Marques Secretarias Municipal e Estadual de Educação, Xinguara, Pará, Brasil arteques@hotmail.com

Resumo Ao longo de décadas, a formação das cidades do Sul do Pará vem ocorrendo por combinações de ciclos econômicos e deslocamentos de população. $\mathrm{O}$ artigo apresenta a experiência de migração daqueles moradores de Xinguara que viveram os tempos iniciais da transformação da cidade e da região, propiciada pelas atividades de extração de madeira, garimpo de ouro e ocupação de terras. Propõe-se que a mobilidade nas e entre as "cidades da borda" amazônicas seja tomada como expressão de um conjunto de valores que concebem a "andança" como parte da vida. Desse modo, entendemos que a análise dos processos urbanos deve considerar as narrativas de vidas em tensão entre fluxos e paradas, os contextos de fronteira marcados por alegrias e desafios do desbravamento do novo, mas também pela violência destrutiva contra certos grupos, ambientes e modos de vida preexistentes.

Palavras-chave: Mobilidade. Migração. Cidades amazônicas. Xinguara.

1 A pesquisa que sustenta este artigo foi financiada pela Fundação de Amparo à Pesquisa de Minas Gerais (FAPEMIG) no período 2013-2015 e resultou na dissertação de mestrado da segunda autora no Programa de Pós-Graduação em Ciências Sociais da PUC-Minas. Nesse período, foram realizadas entrevistas com moradores antigos, conhecidos da pesquisadora ou indicados por seus interlocutores. Algumas entrevistas foram conduzidas com alunos do $3^{\circ}$ ano do Ensino Médio de escolas públicas e particulares de Xinguara, os quais fizeram parte do conjunto de 300 questionários aplicados na pesquisa para conhecer a percepção dos mais jovens sobre a história do lugar. Neste artigo, privilegiamos o primeiro conjunto de informações. 


\section{Introdução}

A formação de uma cidade amazônica tal como narrada por moradores que viveram os processos iniciais de sua emergência, enquanto nó onde se encontram variados percursos de deslocamentos, é o eixo deste artigo. A cidade de Xinguara (PA) e sua condição de entroncamento de estradas e percursos de mobilidade são apresentadas sob a perspectiva da migração e suas diversas modulações temporais por esse cenário das terras sul-paraenses.

Entendemos que a característica da vida móvel pode ser tomada como dado duradouro da vida xinguarense. Ainda que moradores chegados há várias décadas tenham sido os narradores privilegiados, atentamos para o fato de que a migração fundadora é elemento de uma composição de fluxos integrados em regimes sociais de circulação mais abrangentes. Por isso, reconhecemos em Xinguara o valor atribuído à andança, registrado em pesquisas sobre o interior do Brasil Central e Amazônia (VIEIRA, 2001; GUEDES, 2013). O migrante de outrora e o morador inquieto da atualidade podem ser abordados de acordo com Thomas Nail, que observa:"[...] more than any other political figure (citizen, foreigner, sovereign etc.), the migrant is the one least defined by its being and place and more by its becoming and displacement: by its movement" (NAIL, 2015, p. 3, grifo original). Por isso, os atos e projetos articulados em função do movimento direcionam a nossa visada sobre a cidade.

Em verdade, na visada dos cientistas sociais tem se conhecido a Amazônia pela investigação de movimentos (frentes de expansão, migrações, construção de cidades, circuitos de produção e consumo), o que inclui os trabalhos sobre as cidades do agronegócio contemporâneo (MARQUES, 2013; 2015; RUMSTAIN, 2012). A partir de Xinguara, vemos a cidade como espaço-tempo modelado por trajetos de indivíduos e famílias que resultam em um interminável arranjo de composições urbanas (MOURA, 2010).

As entrevistas realizadas na cidade com moradores reconhecidos como pioneiros se demoram sobre a cinética da vida local: os agentes e as atividades que demarcam o processo de fazer cidade, de fazer a vida na fronteira dos primeiros tempos da pequena cidade que se situa entre rios e terras vastas. Dizem ainda sobre a impermanência das vidas diárias, que persistem no movimento por escolha ou por obrigação.

Nesta visada sobre Xinguara, insistimos que a cidade e seus entornos são espaços que se fazem ao longo do tempo, enredando pessoas, árvores, gado, minérios, máquinas, tratores, aviões, sementes, inseticidas, armas e cercas. Afinal, são essas as partes da trama da vida narrada por homens e mulheres que fizeram em Xinguara sua casa ou uma de suas casas. A aproximação que aqui se faz às lembranças dos migrantes segue a observação de Doreen Massey (2013, p. 189) de que

no contexto (pelo menos até recentemente) de interpretações hegemônicas da memória, as mais prováveis conotações são para o individual internalizado ou a noção de história pode muito bem ser a história singular. Realçar a espacialidade de nossos passados e a geografia de nossas histórias - a dispersão 
de nossos próprios selves - inclui uma interpretação com mentalidade mais aberta, na qual todas essas coisas são, necessariamente, constituídas por e através de contatos, relações e interconexões com outros.

Nesse rumo interpretativo, seguimos o curso definido nas narrativas e suas demarcações dos episódios, personagens e cenários que nos contam da fronteira como experiência e como projeto incessante. Para tanto, apresentamos antes as paisagens nas quais se enlaçam esses movimentos e biografias.

\section{O sul do Pará e a cidade de Xinguara}

A cidade de Xinguara localiza-se na Mesorregião Sudeste Paraense, delimitação geográfica formalizada pelo IBGE que reúne 39 municípios, conforme pode-se ver no mapa abaixo. Entretanto, usaremos a designação corriqueira de sul do Pará como referência à sua localização no estado. O município foi criado em 13 de maio de 1982, a partir do desmembramento do município de Conceição do Araguaia. Em 2010, contava com uma população de 40.573 habitantes.

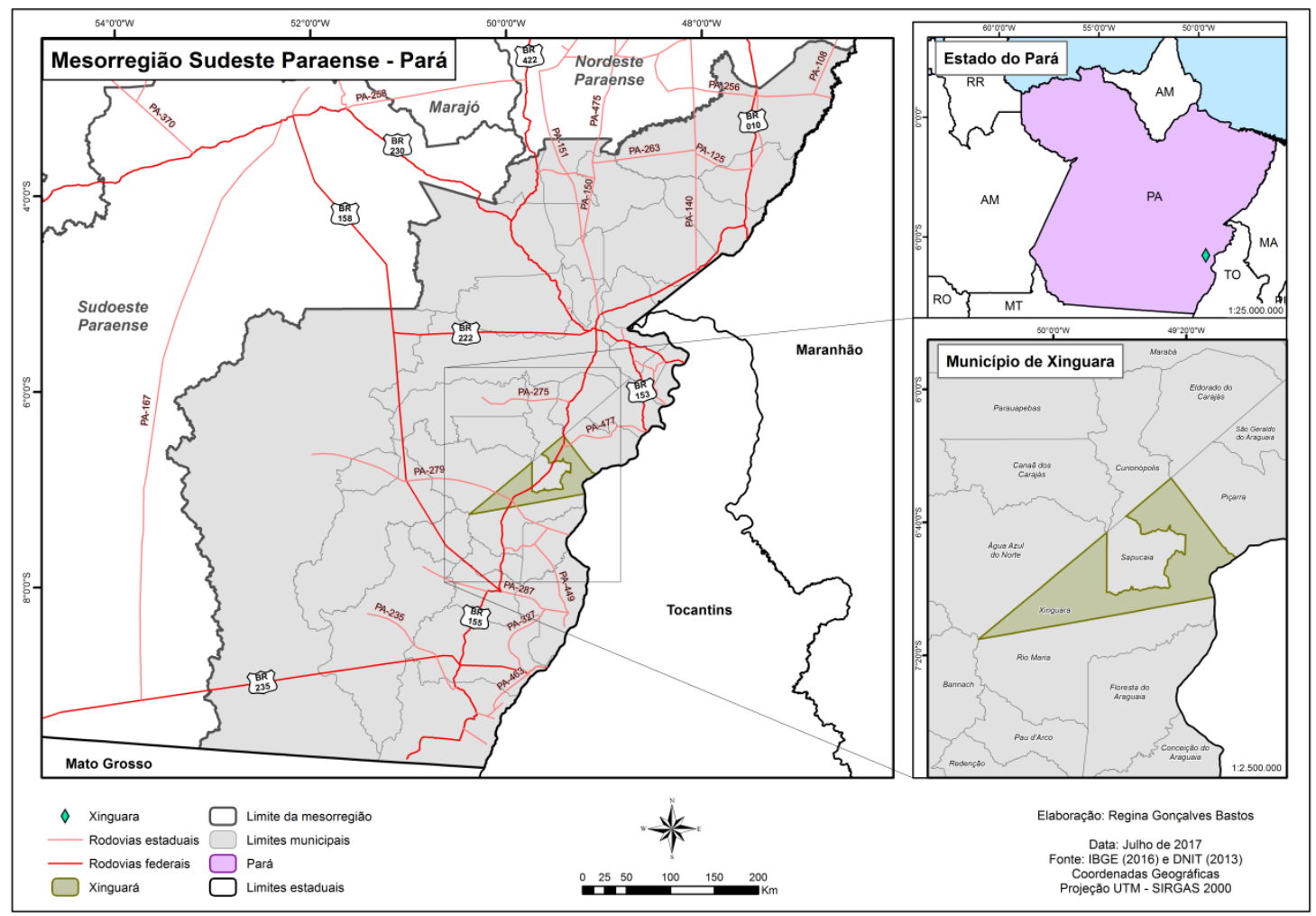

A pesquisa que dá origem a este artigo dedicou-se a conhecer as formas de ocupação da cidade de Xinguara e de cidades próximas no trajeto da rodovia PA-150, ligando Conceição do Araguaia, Redenção e Rio Maria. Estas últimas cidades surgiram no mesmo período e contexto, interligadas e integradas em função do corredor migratório existente pelo menos desde os anos 1970. Foram investigados os processos de mobilidade de uma 
população flutuante, sendo característico na região o ir e vir de pessoas e coisas. Estes trajetos de deslocamento que passavam por Xinguara foram captados principalmente nas entrevistas, realizadas entre 2013 e 2014, com moradores reconhecidos como "pioneiros", dentre os quais encontramos migrantes que vieram em busca de terra, em função da madeira (trabalhadores e proprietários de madeireiras), motivados pela exploração do ouro. Uma segunda leva de pessoas veio em busca de terra em meados da década de 1980, no contexto dos investimentos no agronegócio, atividade predominante na cidade atualmente.

As narrativas que trazemos contam sobre os lugares, as pessoas, os modos de vida; falam do espaço e do tempo em constante mudança na região, pois a cidade se formou no entroncamento entre rodovias, povoamentos e fluxos de deslocamentos ainda em atividade nos tempos atuais. No decorrer dos anos, de 1980 a 1990, foram se instalando as mineradoras, sendo alterada a estrutura fisica e demográfica de outros municípios, como Canaã dos Carajás e Ourilândia do Norte, atraindo populações diversas e mantendo uma parcela dessas pessoas flutuante dentro da própria região, em função da busca de outras oportunidades de trabalho, uma vez que houve a decadência e/ou a estagnação das "febres econômicas": do ouro e da madeira, por exemplo.

Nesse processo, acontece o surgimento e crescimento dos núcleos urbanos com um contingente de pessoas vindo de muitos lugares, dando origem às "cidades da borda da região, povoadas por forte contingente nordestino" (BECKER, 2013, p. 52). Para Bertha Becker, tratam-se de núcleos localizados em posição de fronteira e que estão ligados por estradas, atraindo forte imigração. Portanto, em Xinguara estamos em uma cidade da borda amazônica, integrada em uma rede de relações com outras cidades mais ou menos distantes. Essa condição não se difere de outras cidades amazônicas, pois "no povoamento da Amazônia sempre predominou o espaço dos fluxos: os núcleos nasceram, cresceram e continuam crescendo como ponto de apoio à circulação de matérias primas exportadas, de bens de produção e de consumo importados, e da população" (BECKER, 2013, p. 45).

Para se entender o processo que ocorreu na construção da cidade de Xinguara, mais que se ater às questões geográficas e físicas do desenvolvimento urbano, é fundamental olhar sociologicamente o contingente humano que foi se constituindo e estabelecendose no tempo, caracterizando o modo de vida dos habitantes que compõem esta cidade, que existe em uma forte correlação entre o urbano e o rural, a exemplo do que José Carlos Pereira observou para outras regiões paraenses (PEREIRA, 2013). Aglomerados de pessoas oriundas de muitos lugares se instalavam em alojamentos de empresas de construção de estradas e empresas madeireiras; em sua maioria turmas de homens que chegavam sem suas famílias para sondar e conhecer a região, movidos pelas notícias de terras baratas e fáceis, espaços abundantes, trabalho farto, muita madeira e ouro. 
As narrativas de quem chegou primeiro confirmam parte dessas características ${ }^{2}$. Os imigrantes ouviam notícias e eram movidos a buscar essas novas estradas recém-abertas pela região norte afora, configurando fluxos migratórios "espontâneos"3. Mesmo com a construção dessas rodovias que atraíam levas de pessoas para a região, muitos destacaram que no percurso até aqui e no início, quando muitos se instalaram, a vida foi dura:

Em 1977, quando entrei aqui pela primeira vez, quando eu cheguei, não era Xinguara, era o Entrocamento [primeira denominação do lugar]. Vim porque ouvia dizer que era bom para começar a vida, só que não foi fácil não aqueles primeiros tempos. Tinha pouquinha casa, aqui tudo era só mata. Então, eu me considero em Xinguara um pioneiro, eu ajudei a construir Xinguara. Porque quando eu cheguei aqui era só mato [...] Tinha muita gente e tinha pouca casa. O povo vinha pra Xinguara porque tinha muita madeira, tinha muito ouro, muito trabalho, então o povo vinha para arriscar a vida para vê se ganhava dinheiro. Bom, aí o povo ia chegando. Quem tinha dinheiro ou trazia um suporte melhor já ia construindo suas residências melhores, mais seguras, mais organizadas. Quem vinha fraco de condições, ia se instalando nos barraquinhos do jeito que dava, quando isso aqui ainda era o Entrocamento do Xingu. Tinha muito daqueles barraquinhos, só de lona, ou só de palha de babaçu, improvisado mesmo, parece que todo mundo estava esperando para ver no que ia dar, não foi um tempo fácil... (V. M.S., 78 anos, morador desde 1977).

Xinguara se fez como muitas outras cidades na Amazônia. Como mostram os estudos de Bertha Becker, "embora cerca de $70 \%$ da população amazônica vivam em núcleos urbanos, a urbanização é negligenciada nos estudos sobre a região" (BECKER, 2013, p. 11). Estas cidades, mesmo surgindo de forma rápida e desordenada, foram propulsoras do crescimento da região, pois "as cidades têm sido cruciais para o desenvolvimento da ocupação e as tentativas de desenvolvimento ali experimentadas"(BECKER, 2013, p. 11).

Essas cidades surgiram pela presença de dezenas de milhares de imigrantes que lançaram suas vidas nesses caminhos. Nesse sentido, Xinguara faz parte da paisagem descrita por Jean Hébette (2004, p. 11), na qual vislumbramos:

a aventura de imigrantes pobres, homens e mulheres, que com crianças e bebês desembarcavam nas precárias estações rodoviárias ao longo da estrada Belém-Brasília com seu patrimônio: carregados de malas e embrulhos, de panelas, de colchões velhos, de alguma ferramenta, em busca de terra para morar e plantar em família.

2 As narrativas dos pioneiros devem ser escutadas a partir do entendimento das condições sociais de produção das lembranças (GUÉRIOS, 2008; POLLAK, 1989). Embora se reconheça alguns tropos nas memórias de moradores chegados há muitos anos, como aqueles ligados ao heró́smo e à vida dificil, outros são apagados, como a referência ao que havia antes (o tema do vazio) e a violência envolvida na conquista, principalmente sobre as populações indígenas (MARTINS, 2012).

3 A crítica à noção de "espontâneo" para distinguir esta forma de migração ou colonização daquela colonização oficial (“dirigida”) foi realizada por Alfredo Wagner Berno de Almeida (1974). De acordo com Otávio Velho, “esse 'espontâneo’ não deve ser tomado ao pé da letra sob risco de mascarar os conflitos sociais envolvidos num processo como esse” (VELHO, 2016, p. 20). 
Nas memórias dos pioneiros, os ciclos econômicos que se desenvolveram em Xinguara funcionaram como atratores de fluxos migratórios intensos: primeiro a madeira, que era explorada em grande quantidade, abriu frentes de trabalho com a instalação de muitas serrarias, tais como Marajoara, Pagnocelly, Peraky, Selectas, Jacafé. Outras empresas menores também geraram mão-de-obra por muito tempo: Serraria Marília, Serraria Paraná-Pará, Madecil, Serraria Xingu, Itaipu, Dimba, Gaviza, entre outras.

Em seguida, quase paralelamente ao auge da madeira, foi descoberto o ouro, ciclo que também atraiu muitas pessoas, que em muitas situações, apostaram tudo que tinham nos garimpos da cidade e região. A terra foi grande propulsora que incentivou mais famílias a chegarem a Xinguara, motivadas pelas propagandas de "Reforma Agrária" na década de 1980, aumentando rapidamente a população do lugar, sendo o principal fator que garantiu maior estabilidade para a população que conseguiu sua aquisição por diversos meios.

Não há dúvidas de que todos os ciclos econômicos que se sucederam na região sul do Pará contribuíram para trazer levas de migrantes para cada cidade que surgiu no auge das "febres" econômicas4. Porém, cabe ressaltar que a disponibilidade de terra foi e é fundamental na formação das cidades na Amazônia. Xinguara tem suas bases fortemente constituídas pela busca da terra. Seu desenvolvimento ao longo dos anos está inteiramente relacionado a essa questão, que forneceu a estrutura econômica atualmente consolidada pela agropecuária. Dizem os moradores antigos que aqueles chegados em Xinguara mais recentemente não sabem o que viveu quem veio primeiro, as enormes dificuldades para alcançar o objetivo de ter um pedaço de terra; como dizem na região, amansando a terra, isto é, derrubando a mata, plantando o capim, abrindo estradas.

As informações dos pioneiros dizem que inicialmente os lotes de terras eram demarcados e distribuídos por uma espécie de agenciador, que era visto como responsável pelo processo de definição das áreas e da forma como deveriam ser entregues esses lotes de terras, seja na área rural, no entorno da cidade ou em lotes urbanos, de acordo com seus próprios critérios. Os pioneiros fazem menção a esses supostos agenciadores, vistos como homens detentores de certa autoridade, bem no início do Entrocamento do Xingu.

No caso de Xinguara, muitas famílias foram motivadas pelas notícias e propagandas de "Reforma Agrária" na Amazônia. Mesmo assim, foram inúmeras as famílias que não conseguiram atingir seu objetivo de ter um pedaço de terra. Muitas até voltaram para seus lugares de origem em função da frustração de não ter conseguido a terra. Porém, muitas famílias ficaram, enfrentaram a nova situação e buscaram outras formas de sobreviver, como no caso que segue:

Cadastrei-me em dois projetos de assentamento pelo GETAT. Costumo dizer que até hoje aguardo assentamento, nunca consegui ser assentado... Posteriormente, após a chegada, em março de 1984, fui morar numa situação inusitada, eu buscando terra, fui ser arrendatário de um posseiro, e ali a gente

4 Para a análise do significado da expressão "febre", largamente utilizada para se indicar o ápice de uma atividade econômica, ver Guedes (2013). 
trabalhou um ano e adquiri a maior terra que pude possuir no Pará: 2 alqueires e meio de terra e, ali consegui viver 5 anos com minha família, costumo dizer que foram os anos mais felizes de minha vida enquanto lavrador, desses dois alqueires e meio de terra, conseguimos produzir muita fartura. Posteriormente, vendemos lá, passamos a possuir no Setor Chácaras um pequeno terreno, onde vivemos até hoje, enfrentamos por muitos anos o trabalho de horticultor, desde março de $1989 .$. feliz por ver meus filhos todos estudando, hoje formados, na época voltei a estudar, fiz magistério e graduação e me tornei professor. Entrei para vida política, fui vereador por um mandato, hoje quase aposentando como servidor público... (J. M F, 69 anos, residente em Xinguara há 30 anos).

Historicamente, a formação da região sul do Pará tem suas bases intrinsecamente ligadas à forma como se deu a colonização da Amazônia como um todo. Esses antecedentes sinalizam não só o isolamento e abandono da região, como também apontam as ações de exploração das riquezas, sem nenhum planejamento, tais como o alto índice de derrubadas de florestas, a substituição da flora por capim e a expulsão e eliminação quase total da fauna de seu habitat. Isso se confirma nos depoimentos dos pioneiros de Xinguara, que presenciaram essa destruição rápida em ações ambiciosas, com utilização de técnicas como a corrente, o trator de esteira e o avião monomotor para jogar o capim e o inseticida.

Para minimizar o isolamento da região sul do Pará inicia-se em 1956 a construção da Rodovia Belém-Brasília. Para se ter uma ideia desse isolamento, chegar até Belém só era possível por via aérea ou marítima. Ou então, numa opção mais complexa e mais penosa, por via terrestre, através de picada aberta na mata, partindo do Maranhão, numa rota longa e demorada. Por essa rota também vinham rebanhos de outras regiões. A implantação dessa importante rodovia federal foi um marco decisivo não só para a integração da Amazônia com o Centro-Sul do Brasil, como também contribuiu de forma significativa para dinamizar o desenvolvimento urbano de diversos aglomerados populacionais no Centro-Norte do Estado de Goiás, além de outras áreas do Norte e Centro-Oeste brasileiros.

A construção da Belém-Brasília é o marco principal para a entrada de grandes levas de migrantes na região Norte; a estrada chegou ao Sul do Pará em 1960 e estava conectada a Conceição do Araguaia e Marabá por estradas não pavimentadas. Em seguida, foram abertas as rodovias estaduais PA-150 (cuja construção foi anunciada em 1966) e PA-279 (com abertura iniciada em 1976), o que provocou a corrida pela terra e estimulou o aumento dos fluxos migratórios. Como afirmam Schmink e Wood (2012, p. 194), "as estradas estimularam um dramático reordenamento espacial, que deslanchou uma transformação na socioeconomia e organização política no sul do Pará”.

Xinguara nasceu exatamente no local em que se instalaram as empresas Andrade Gutierrez e CONTERPA, que construíram a rodovia PA-279, segundo informações dos próprios pioneiros.Vieram pessoas de todos os lugares do Brasil e de todas as classes sociais: nordestinos em busca de trabalho e fugindo da seca; trabalhadores rurais e pequenos agricultores em busca de terra para firmar e garantir melhorias de vida e sustento de 
suas famílias; médios e grandes fazendeiros em busca de terras maiores para ampliar seus negócios e dar um futuro melhor para suas famílias, comerciantes que se instalaram para tirar proveito na venda de produtos e mantimentos básicos em função do aumento populacional e do dinheiro que já vinha circulando em razão da exploração vegetal (borracha, castanha e madeira) e do acesso à terra.

Assim surgiu o Entrocamento do Xingu. A encruzilhada onde surge o povoado cresce velozmente. Sabe-se que "em fevereiro de 1977, menos de um ano depois de sua fundação, Xinguara abrigava 1360 residências, 30 lojas varejistas, 25 bares e restaurantes, 15 açougues, 6 farmácias e 5 igrejas protestantes" (SCHMINK; WOOD, 2012, p. 225226). Nesses tempos iniciais, os pequenos aviões que desciam no aeroporto improvisado na avenida Xingu, entrada da cidade, carregavam tudo que era necessário para implantar as primeiras lojas, serrarias, hospitais e faziam transporte de passageiros, principalmente de garimpeiros ou de doentes com malária. Conta-se que aqueles que não tinham condições de pagar a passagem aérea em dinheiro, usavam gramas de ouro como moeda.

Nesse novo lugar se encontra gente muito variada. Ouve-se repetidamente dos entrevistados que em Xinguara a cultura é diferente dos locais de onde vieram, que em seus locais de origem todos seguiam um tipo de tradição relativamente estável. Nas falas de alguns pioneiros registramos o seguinte:"a cultura, aqui não é igual em outros lugares que guardam a tradição. Até a festa junina daqui é diferente, fazem umas danças diferentes... não é igual do nosso tempo no nordeste" (J.S.L., 58 anos, morador há 28 anos). Em outra fala: "nunca vi aqui uma festa, uma dança da cultura do sul igual vi quando eu era moça, eu ia nas festas lá todos os anos tinha a tradição mudava muita coisas, mas os costumes era os mesmos. Aqui é meio misturado, até o jeito do povo dançar forró é diferente" (M.B.S., 51 anos, moradora há 30 anos). Em outro comentário, diz-se que "até os gaúchos e paranaenses que vieram para cá vão se acomodando, não usam mais o estilo de vida de lá, no mínimo usam o chimarrão, para não perder o costume e é só também” (S. H. C., 58 anos, moradora há 31 anos).

O fato de ser uma cidade marcada desde o início de sua história por fluxos migratórios intensos, advindos de muitas regiões brasileiras, ocasionou o processo de ocupação socioespacial por uma população marcada pela pluralidade cultural, de resto comum a toda região sul-paraense. Xinguara tornou-se uma cidade onde notamos a formação de "identidades misturadas". Utilizamos esse termo para o contexto de Xinguara a partir do trabalho de João Pacheco de Oliveira (1998). Sua análise está relacionada aos indígenas do Nordeste, mas cabe para essa reflexão no que toca à questão da impossibilidade de uma coletividade pura, depois de tanta alteração no contexto de vida e na subjetividade de todos.

A convivência entre populações migrantes foi consolidando hierarquias de classificações regionais, evidenciando categorias etnicizadas, como os maranhenses no sudeste do Pará e, particularmente em Marabá, estudados por Idelma Santiago da Silva (2006, 2010). Desse modo, sabemos que essa mistura cultural proporciona as "trocas e redefinições de esquemas culturais" (VIEIRA,2001,p.119) entre aqueles que se deslocam, 
mas ela também está entrelaçada com processos de dominação simbólica evidentes na circulação de termos depreciativos para referência a pessoas e seus costumes. Esse é um dos efeitos do fluxo de pessoas que resulta na coexistência que compõe a paisagem antropológica dessas cidades, na qual se destacam outras dinâmicas.

\section{Tempos de migração e a construção da cidade}

As características urbanas de Xinguara são marcadas por diferenças econômicas, sociais e culturais que influenciaram o modo de vida. Assim, a formação de vínculos e valores acontece em um contexto de diferenças e desigualdades sociais que se revelam não só no modo de viver, mas também na formação material da cidade, na composição dos bairros e na fixação de seus habitantes.

De acordo com as falas de diversos moradores pioneiros, percebe-se que, desde o Entroncamento do Xingu, ocorreu uma rápida transformação do espaço e formou-se um intenso aglomerado de pessoas, como se fosse um grande acampamento improvisado com várias casas de palhas e muitos barracos cobertos de lonas de plástico preto.A notícia de distribuição de terras gerou a fase de migração de pessoas, principalmente vindas de Minas Gerais, Goiás, Piauí e Maranhão. Em pouco tempo, o Entroncamento do Xingu se transformou em uma vila, com casas de madeiras que mais pareciam caixotes que iam sendo construídos nas ladeiras do povoado; ainda restam muitas dessas casas até hoje em vários bairros da cidade.

Houve época em que a via de acesso intrarregional e para fora da região era pelo rio Araguaia, com os produtos conduzidos por canoeiros. Depois essas vias foram se ampliando, uma vez que "ao andamento do rio acrescentaram-se e superpõem-se outros andamentos. São principalmente o caminhão e o automóvel que conferem outro ritmo à economia e à sociedade" (IANNI, 1978, p. 97).

Xinguara está fortemente ligada à história da centenária cidade de Conceição do Araguaia, considerada nesse contexto como "Cidade Mãe", cidade que é a porta de entrada para o crescimento da região sul do Pará.

Ao longo dos anos 1960-77, a economia e a sociedade de Conceição do Araguaia modificaram-se em ritmo cada vez mais rápido. E as modificações alcançaram progressivamente todas as relações e atividades sociais. Nada ficou à margem da modificação, nem a vida cotidiana do caboclo lá no meio do mato, nem os interesses econômicos ou políticos dos donos do lugar (IANNI, 1978, p. 97).

A população de Xinguara cresceu rapidamente, configurando-se numa urbanização aparentemente desordenada. Na localidade, quem mandava era o mais forte. Como apontam Marianne Schmink e Charles Wood (2012, p. 228), "Xinguara tornou-se amplamente conhecida pelos tiroteios que ocorriam regularmente em suas ruas e pela impunidade com que os pistoleiros e escroques atuavam". Esse aspecto também foi ressaltado por uma moradora: 
Que eu me lembre tinha muita violência, por causa de terras. A Tupã Ceretã foi uma gleba que surgiu com muita violência e muita gente morta. Eu me lembro quando eu morava em frente onde hoje é o ginásio de esporte e lá antigamente foi primeiro cemitério, vi muita coisa ali. Uma vez era 3 horas da manhã não tinha onde velar os corpos dos pistoleiros nem cova aberta, acabou amanhecendo o dia em cima de um monte de terra que tinha (S.A.S, 48 anos, moradora há 28 anos).

Os entrevistados dizem que a violência era comum. Por causa do medo, muitos moradores foram embora, voltaram para suas terras de origem porque não queriam ver seus filhos crescerem em uma terra que parecia não ter lei. Schmink e Wood (2012, p. 228) relatam ainda que "depois de um tempo, indivíduos bastante carismáticos passaram a controlar o povoado. Bem ao estilo da fronteira, eles utilizavam uma mescla de violência e clientelismo para estabelecer sua autoridade".

Analisar Xinguara a partir das narrativas de muitos pioneiros é como visualizar um álbum de fotografias mais antigo que vai mostrando como tudo era antes: as pessoas, o lugar, a paisagem. A segunda autora lembra quando chegou a Xinguara com a família em 1984, com dez anos de idade, vindos de Barro Alto (GO), onde haviam se encontrado seus pais, filhos de famílias numerosas nascidas em Minas Gerais e Piauí:

Tenho presente, por exemplo, quando entrei em Xinguara pela primeira vez, quando ficaram em minha memória de infância os montes enormes de serragens que atingiam metros de altura na entrada da cidade. Recordome da quantidade de toras de madeiras empilhadas à beira da estrada PA150, dentro do perímetro urbano. Era muita madeira e que parecia nunca acabar, o forte cheiro daquela madeira verde que exalava no ar. Era tanta serragem que parecia que a única alternativa era queimá-la para se livrar dela e desocupar espaço para novas quantidades que se formavam a cada dia; dessa queima outro cheiro forte se espalhava e formavam-se fortes nuvens de fumaça pela cidade afora. Eram pelo menos umas quatro serrarias grandes instaladas naquele trajeto, por coincidência minha família ficou morando alguns dias na casa de parentes nesse espaço que era um ambiente de muito barulho das serrarias e das catracas dos caminhões, que despejavam madeiras o dia inteiro e parecia que a noite toda também. (A.F.M., 46 anos, moradora desde 1984)

A entrevistada a seguir relata o que foi a situação de muitos moradores, transitando entre atividades e experimentando relações “dionisíacas” com o dinheiro:

Meu pai veio com o objetivo de poder lidar com a madeira que aqui era mais fácil, mais barata e ele mexeu com a serraria e a marcenaria durante bom tempo, era pequeno negócio, mas rendia. Com o tempo ele viu que madeira não tinha retorno para ele que era um pequeno empresário, concorrendo com os maiores não dava mais lucro. Aí ele migrou logo para a área de garimpo, só que ele mexia com garimpo lá para o rumo de Tucumã. Na época ele tirou muito ouro e lá foi onde a cabeça dele desviou, ele começou a entrar no mesmo ritmo desse povo que não tinha família, ganhava o dinheiro ia na rua e gastava tudo (M.B.S., 51 anos, moradora desde 1979). 
O mercado da madeira movimentou Xinguara. Foi um período em que muitas famílias se estabeleceram, construíram suas casas e se organizaram em função dessa frente de trabalho que perdurou por mais de uma década. Nos relatos dos moradores pioneiros tem-se uma dimensão do contexto em análise:

$\mathrm{Eu}$ fiquei muito impressionada que, quando eu cheguei, aquele espaço que hoje é a Praça da Bíblia próximo ao Banco do Brasil era onde se colocava as madeiras que vinha do mato, porque não comportava tudo no espaço das serrarias. Muitas toras cortadas que os pessoal trazia, era descarregada ali de madeira, quando a gente saia na porta de casa estava aquela montoeira de toras cortadas para levar pras serrarias. $\mathrm{O}$ que me impressionou muito foi as madeiras amontoada pra ser levada para as serrarias. Os caminhões madeireiros eles erguiam aquelas toras todas na catraca, os homens tinham que ser bem fortes pra conseguir puxar no cabo de aço até conseguir encher todos os caminhões. Passavam a noite e o dia todinho um barulho estranho dos cabos de aço era um serviço muito perigoso, os cabo de aço rebentava as toras caiam um risco muito grande de cair em cima de uma pessoa. Então nunca saiu da minha cabeça aquele barulho que se repetiu por muitos e muitos anos, noites e dias sabe assim aquele:"trac, "trac", "trac", era o barulho das catracas dos caminhões para tirar ou colocar as toras do caminhão. Aí acabou, as coisas mudaram as serrarias fecharam aos poucos e Xinguara foi ganhando outros rumos. As coisas mudaram muito por aqui (T.R.L.A, 46 anos, moradora desde 1983).

Havia uma intensa movimentação de pessoas indo ao trabalho nas serrarias em Xinguara. Na época das madeireiras era expressiva a quantidade de ciclistas que percorriam o trajeto das rodovias, avenidas e ruas da cidade. A bicicleta era o meio de transporte mais utilizado na cidade na década de 1980 até meados da década de 1990. Hoje se vê uma quantidade mínima de bicicleteiros pelas ruas na cidade. A bicicleta foi aos poucos substituída pelas motos, vistas em grande quantidade, sendo o meio de transporte mais popular na cidade atualmente. Embora esse meio de transporte popular se misture à grande quantidade de caminhonetes que são muito utilizadas principalmente pelos pecuaristas, empresários e comerciantes de Xinguara e região, caracterizando o poder econômico e o status de uma parte significativa da população xinguarense. Essas informações mostram a adaptação de hábitos no modo de vida dos moradores, que seguem o ritmo das mudanças proporcionadas pela própria alternância dos ciclos econômicos que marcam a vida da cidade.

A construção da cidade de Xinguara deve-se também à fase do ouro. Apesar de ter sido uma fase rápida, deixou marcas para a população, além do sonho de muitos que vieram com esse objetivo, sem conseguir realizá-lo, mas que acabaram ficando e arrumando outras formas de sobreviver na cidade. Enquanto alguns que vieram de lugares longínquos e acabaram voltando para suas terras de origem, houve muitos outros casos de aventureiros que já estavam acostumados a perambular de um lado para outro, de garimpo em garimpo. Conta-se que a população de Xinguara cresceu significativamente entre 
1983 e 1989 em função dos pequenos garimpos que surgiram na região; esse crescimento coincide com o da região do garimpo de Serra Pelada.

Nos depoimentos percebe-se que os garimpos para estes trabalhadores migrantes eram só uma atividade alternativa para tentar ficar rico ou para garantir uma estrutura mínima de que necessitavam, o que se traduzia em ter uma casa própria para morar. Muitos migrantes que recorriam aos garimpos alimentavam consigo o sonho de atingir uma vida melhor através da aquisição do ouro; no entanto, o objetivo maior era o de conseguir um pedaço de terra ou um trabalho fixo para dar sustento e vida digna e sossegada à família.

As informações apontam que os garimpos que existiram no município estavam situados dentro de fazendas e pequenas propriedades sob controle de proprietários que permitiam a garimpagem, mas sempre trabalhando num processo de porcentagem do ouro que era extraído. Entre os principais garimpos do município de Xinguara, destacam-se os seguintes: do Mamão, do Babaçu, do Sequeiro, do Ageu, do Américo e o último deles, já na década de 1990, foi o Garimpo das Malvinas, bem próximo ao perímetro urbano da cidade.

Contudo, foi o ciclo da terra que se consolidou como base principal para a expansão da cidade de Xinguara, resultando numa interligação inseparável entre o rural e urbano. A atividade pecuária, reconhecida por ter trazido o progresso e o desenvolvimento, foi se consolidando paulatinamente (DURÃES, 2014). A chegada de levas de migrantes a partir da década de 1980 foi um processo acelerado e, ao mesmo tempo, desordenado. Foi como uma avalanche a derrubada das florestas: "matou o babaçu com a cultura da pecuária", como canta José Neto, dando lugar a extensas pastagens. A fim de efetivar rapidamente a formação de pastos para o gado, foram utilizadas técnicas para serem espalhadas as sementes de capim pela região, usando-se o avião monomotor. Com as matas já no chão, depois das derrubadas e queimadas, os aviões passavam derramando e espalhando as sementes, em pouco tempo transformando por completo a paisagem. Dessa forma, a mata dos arredores de Xinguara deu lugar a extensas pastagens para a criação do gado bovino. Assim conta um pioneiro:

Quando cheguei aqui neste lugar, Xinguara era só mata em volta. A gente convivia com o barulho dos guaribas. Ouvia muito o esturrado das onças pintadas aí perto. Ali onde é a Avenida Xingu, pra cima da Igreja Católica, era tudo mata, só era os carreadores dos caminhões madeireiros. Assim, de um ano para o outro, tudo aqui em volta foi sendo derrubado, logo ia virando pastos porque gente que vinha mais de Minas Gerais e Goiás e até do sul prá cá, tinha interesse em comprar terra e fazer pastos pra criar gado. Essas matas foram se acabando muito rápido. Eu cansei de ver os aviões desse tipo bimotor passar por cima aí jogando semente de capim colonhão (J.S., morador desde 1979).

A exploração da terra, representada de forma marcante pela pecuária, é o ciclo predominante que contribuiu mais fortemente para a construção e reorganização das cidades sul-paraenses. Também foi elemento propulsor que motivou inúmeras famílias 
a virem para o município de Xinguara. Para organizar esse processo de distribuição das terras, por exemplo, foi criado o Grupo Executivo das Terras do Araguaia-Tocantins (GETAT), pelo Decreto-lei no 1767 , de 19805. Os focos de atuação foram a demarcação e a distribuição de terras e títulos de propriedades, assentando muitas famílias. As principais áreas que até hoje existem com pequenos e médios proprietários são os assentamentos Tupã, Gleba 10, Vermelho e Preto, Araguaxim, Araguari; entre outros que foram se reorganizando posteriormente. As colônias Cruz de Pau, Barreiro Preto, Marajoara, Cachimbão e outras são áreas que abrigam muitas famílias de pequenos produtores que vieram principalmente do estado de Goiás.É importante registrar que esses espaços rurais estão interligados à cidade porque estão perto da área urbana; as famílias, em sua maioria, permanecem e sobrevivem da agropecuária e da agricultura familiar, destacando-se que muitos de seus filhos vêm para a cidade todos os dias para estudar.

Muitas famílias que haviam conseguido um pedaço de terra, geralmente comprando em espaços já calmos, como dizem na região, "terras já amansadas pelos posseiros", aos poucos foram desistindo e vendendo por razões diversas. Podemos destacar: a falta de estrutura suficiente para investir e permanecer na terra, a falta de estradas, as enormes distâncias, o isolamento, a terra que não era tão fértil e/ou não se adaptava para muitas lavouras que esses pequenos e médios proprietários que vieram do Sul, Sudeste e, principalmente, Centro-Oeste, estavam acostumados em suas regiões de origem.

Mesmo os fracassos nos projetos familiares e pessoais estimulam novos movimentos. Embora a ocorrência dos ciclos econômicos e suas temporalidades mais e menos quentes seja uma face de Xinguara, os episódios de desaceleração relativa ou de frustração de expectativas não alteram a percepção de que a vida da cidade é de progresso contínuo. A seguir, refletimos sobre os valores que alimentam o estar no mundo olhando para o futuro, tão notável nas urbes amazônidas como Xinguara.

\section{"Cultura da andança" e a vida em Xinguara: o movimento como valor}

O espaço geográfico em que se encontra Xinguara está interligado ao longo do percurso com os municípios do sul do Pará, nos quais a proximidade e vias de acesso entre si facilitam a mobilidade dentro da própria região, para o sudeste do Pará e até mesmo para outros estados, como é o caso do Tocantins, Goiás e Maranhão. Por isso, mesmo antes da chegada da política de integração da Amazônia, grupos de imigrantes avançaram Amazônia Oriental adentro, constituindo o sul do Pará. Dentre os autores que contribuem para compreender este contexto, Maria Antonieta da Costa Vieira desvenda muitas mobilidades anteriores àquelas que conhecemos hoje, tais como os movimentos de comunidades camponesas orientadas por profecias como as Bandeiras Verdes (VIEIRA, 2001). As informações de seus estudos sobre essa temática são contundentes para afirmar

5 Para a análise dos processos socio-históricos e institucionais envolvendo a distribuição de terras no Pará, recomendamos o estudo de Camila Penna (2015). 
que a "cultura da andança", existente ainda hoje, tem suas bases elementares em raízes históricas por ela recuperadas.

A autora mostra como o território se constrói como espaço sagrado e projeto coletivo para um campesinato que tem a marca forte da migração, destacando o significado que o deslocamento e a ocupação de novas terras assumem para os camponeses da Amazônia Oriental. Mesmo que se tenha pouco conhecimento sobre as Bandeiras Verdes na região, interessa-nos que o processo de mobilidade também possui relações com o aspecto da religiosidade e da profecia. Movimento e andança que ocorreram muito antes da chegada das frentes de colonização nessa região (VELHO, 1972).

As motivações para o ir e vir das pessoas, antigamente e nos dias de hoje, remetem à busca de um lugar pensado no imaginário como lugar das oportunidades, da riqueza de recursos naturais e grandes extensões de terras disponíveis, sendo essa a razão principal dos fluxos migratórios e da mobilidade intrarregional.

André Dumans Guedes realça o vocabulário que expressa o sentido dessas idas e vindas da população em fluxo: "Ficar; ou partir - andar, correr, rodar, rasgar, sair por aí, abrir ou espalhar no mundo" (GUEDES, 2013, p. 30), são registros das falas do cotidiano dos entrevistados de sua pesquisa no Norte de Goiás, que são assemelhados ao andar do processo de migração interna na região sul do Pará. Embora os registros históricos dessa ocupação da região sul-paraense, principalmente na busca por um pedaço de terra, mostrem que o sonho por esse sossego e estabilidade foi perseguido com atropelos na vida dessas inúmeras famílias pioneiras. Como analisa Airton dos Reis Pereira, a luta pela terra "envolveu as disputas entre trabalhadores rurais e fazendeiros, empresários ou comerciantes pela apropriação da terra de áreas devolutas e mesmo de imóveis com títulos definitivos ou de aforamentos" (PEREIRA, 2013, p. 13).

A formação da região ao longo do tempo ocorre dessa forma, em se tratando da luta pela terra, em todo sul do Pará: "uma história de violência e de fortalecimento de estruturas locais de poder, baseadas na propriedade da terra" (SOUZA, 2002, p. 6). A violência, portanto, tem relações diretas com a questão da mobilidade, deixando marcas profundas na história das migrações na região.

Torna-se imprescindível compreender este processo da "cultura da andança" ainda existente em Xinguara e na região sul do Pará. Antonieta Vieira (2001, p. 111) esclarece sobre as práticas de deslocamento na região:

A história de vida dos camponeses da região sul do Pará está crivada de deslocamento, sendo comum a presença de várias mudanças numa mesma geração.Esta andança não significa nomadismo, significa uma vida marcada por mudanças: em vários níveis, de lugar, de relações, de atividades. A Amazônia Oriental tem se constituído em um lugar de projeção de sonhos e esperanças para migrantes vindos de todos os lados, especialmente nordestinos.

André Dumans Guedes (2013, p. 37) insiste que andar pelo mundo caracteriza valores próprios; diz ele: 
Levemos a sério, assim, a idéia de uma cultura da andança, ainda que considerando o termo "cultura" num sentido fraco, sem a conotação de totalização que com frequência o marca. Pois ao fazê-lo, a mobilidade aparece antes (ou não apenas) como conseqüência, reflexo ou implicação de fenômenos ou processos que são, lógica e cronologicamente, anteriores a ela; mas (também) como algo que possui valor em si mesmo.

Por esta ótica é que abordamos a história de vida dos habitantes de Xinguara, marcada por muitos deslocamentos anteriores e atuais. Neste lugar, parte da população ficou ao longo do tempo sem condições de se fixar, principalmente tratando de alcançar o acesso à terra ou esperando oportunidades de trabalho, o que resultou, na visão de Bertha Becker, em uma categoria de trabalhadores polivalentes, cuja flexibilidade é "a base do processo de expansão da fronteira" (BECKER; MIRANDA; MACHADO, 1990, p. 19). Na coleta de informações dos próprios entrevistados, isso se confirma:

\begin{abstract}
Meus pais vieram de Minas para Rubiataba, Goiás. Meu pai trabalhava de caminhoneiro... deixou essa vida e resolveu montar seu próprio negócio, onde ele comprou uma serraria e mudou para Mozarlândia, também em Goiás. Lá ele começou como comerciante autônomo, onde moramos durante sete anos. De Mozarlândia que viemos para Xinguara, viemos porque meu tio que morava em Rubiataba já tinha fazenda aqui em Xinguara, ele via a grande variedade, a beleza e a riqueza porque gosta da terra e sonha em adquirir fazendas e mexer com gado. E, as grandes madeireiras que aqui na época era o auge, a febre do momento era muita madeira. Meu pai veio primeiro em 1978 conheceu, gostou demais daqui. Voltou em 1979 com toda a familia (M. B. S., 51 anos, moradora há 32 anos).
\end{abstract}

Xinguara é marcada por esta característica comum das cidades sul-paraenses, ligadas pelos fluxos migratórios, resultado dos ciclos econômicos, suas alternâncias, sucessões e coexistências. Em algum momento na história, a dinâmica de deslocamentos esteve mais forte e predominante mais em uma cidade que em outra, seja pela oferta de serviços e empregos, seja pela oferta de concursos públicos ou vagas em empresas privadas. Esses deslocamentos também ocorreram e ainda ocorrem em algumas circunstâncias: na busca de atendimentos e serviços em órgãos governamentais instalados em Conceição do Araguaia e, principalmente em Redenção, como era o caso do posto do INSS e da Caixa Econômica Federal, na cidade de Redenção. Esse fluxo de idas e vindas diminuiu porque Xinguara recebeu há poucos anos os referidos órgãos que atendem com maior expressividade a população em torno da PA-279.

Outro fator relevante nesse processo de mobilidade é a exploração mineral, atividade em ascensão nos municípios de Ourilândia do Norte, que fica ao sul, e Canaã do Carajás, que fica no sudeste do Pará, mas faz divisa com o município de Xinguara. Além de estradas vicinais que interligam esses municípios, a proximidade geográfica e o acesso interno facilitam as frequentes idas e vindas das pessoas que trabalham nas mineradoras e têm residência fixa em Xinguara. Assim vive o pai de uma entrevistada: 
Meu pai sempre foi motorista e operador de máquina nessas empresas de mineração. Nós sempre moramos em Xinguara. Eu e meus irmãos nascemos aqui. Mas desde que eu sei meu pai fica aí nesse vai e vem pelas empresas que ele trabalha. Um tempo em Parauapebas, já trabalhou em Altamira, em Ourilândia, agora está em Canaã dos Carajás. Ele trabalha pelo que sei com estas máquinas grandes de escavação do solo, para tirar minério, aqui em Xinguara não tem serviço para ele, aí tem que ser assim, é para onde mandam ele tem que ir. Meu pai sempre diz que para sobreviver tem que viver no mundo e a gente acostumou assim (aluna do ensino médio de escola estadual, 17 anos).

Mais um aspecto do panorama da mobilidade local é a grande quantidade de jovens, filhos da cidade, que saem para estudar em outros tantos lugares ou em busca de mais oportunidades de trabalho, além das fazendas, frigoríficos e laticínios, que são as principais ofertas de emprego no município hoje em dia. Muitos jovens da cidade estiveram estudando nas capitais (principalmente em Goiânia, Palmas e Belém do Pará) ou em outras cidades como Araguaína (TO), Gurupi (TO), Porto Nacional (TO), Rio Verde (GO), Anápolis (GO), Marabá (PA), Parauapebas (PA) e outras. Assim, muitos desses jovens retornam para Xinguara profissionalizados, montam o próprio negócio ou são empregados nos espaços que exigem mais qualificação.

A diversidade de relações sociais construídas a partir das diferentes correntes migratórias configura a região sul do Pará e, especificamente, o modo de vida da população xinguarense, que se fixou e, ao mesmo tempo, tornou-se flutuante, isto é, originando uma população caracterizada pela "cultura da andança". São muitos habitantes que possuem residência em Xinguara, mas que vivem em processo de mobilidade pela região, por outros estados brasileiros e até mesmo fora do país.

Migrantes que se cruzam e entrecruzam nos caminhos, que vêm sendo socialmente construídos nessas andanças, nesse ir e vir da população sul-paraense. Uma dessas muitas experiências confirma-se na fala de uma moradora entrevistada:

Ih! Nós andamos muito, mudamos muito quando chegamos na região: primeiro foi a fazenda Santa Isabel, depois pra fazenda Pachibal, depois foi para o garimpo que chamava garimpo do "Bezerro Queimado", que era município de Rio Maria, bem perto de Rio Maria. Depois nós foi para outro garimpo aqui em Xinguara, não me lembro o nome, porque era muitos garimpos que surgia dentro das fazendas aí em volta do município. Aí um tempo nós cansamos da vida de garimpo, resolvemos voltar a plantar horta, plantar lavoura de tomate em terra arrendada. O Profirio meu marido, foi o maior plantador de tomate da região. Aí a gente vivia andando fazendo a venda de tomate, não só pra revendedores aqui da cidade, a gente fazia entrega na região: Rio Maria, Redenção, Tucumã, Ourilândia, Conceição do Araguaia e até para Araguaína nós fazia entrega de caixas de tomate. Aí nós pegou um dinheiro que juntamos do garimpo e compramos esta chácara pra plantar horta (I.N.S, 54 anos, moradora desde 1981). 
É uma característica muito presente entre a população sul-paraense ficar indo de um lugar para o outro, em busca de trabalhos temporários, seja em seu próprio município ou fora deste, geralmente em função de trabalhos sazonais que estão disponíveis em fazendas, em construção de estradas, em mineradoras na região ou em acampamentos do Movimento dos Trabalhadores Sem Terra (MST). Há ainda uma quantidade significativa de moradores de Xinguara em busca de efetivação no serviço público de municípios vizinhos. O processo ocorre de forma contrária também: há os que residem em outros municípios, porém trabalham em Xinguara no setor público ou em empresas privadas. Há moradores com residência fixa em Xinguara que têm comércios ou propriedades rurais, bem como pequenas, médias e até grandes empresas, mas recorrem a outros municípios e regiões para ampliar os negócios. Na cidade estão instalados grupos empresariais e lojas de grande porte como as Lojas Leolar, Armazém Paraíba, Feirão de Móveis Magazine, Localiza, redes de farmácias como a Big-Ben, que estão em Xinguara e em filiais pela região, ocorrendo também a mobilidade de muitos funcionários dessas empresas.

A mobilidade característica da população flutuante está ligada à inquietação de quem ainda não conseguiu alcançar os seus objetivos, ou seja, pessoas que vieram buscar nesta cidade e região, por exemplo, o sonho de ter um pedaço de terra. Para retratar este ponto de vista, apresenta-se a história de vida de D. Maria, do Sr. Domingos e de seus filhos, que já moraram em tantos outros lugares na região sul do Pará (Tucumã, Ourilândia, Rio Maria, hoje residem em Xinguara e, ao mesmo tempo, em Eldorado dos Carajás). Ainda possuem residência em Xinguara, mas compraram terras no município de Eldorado do Carajás, que fica a sudeste do estado do Pará. Ficam indo e vindo entre Xinguara e Eldorado, porque ela é servidora pública, merendeira em escola na rede municipal; o Sr. Domingos foi horticultor por muitos anos. Os cinco filhos são todos nascidos em Xinguara, cada um trabalhou em serviços diversos; todos concluíram o ensino médio, três das filhas concluíram o ensino superior, o único rapaz concluiu o ensino médio e foi cuidar da propriedade rural junto com o pai, comprada no municipio de Eldorado. O rapaz ainda ganha uma renda extra como Agente Comunitário de Saúde Rural (ACSR), enquanto a mãe e as quatro filhas, cada uma em seus respectivos trabalhos, iam investindo na terrinha que era o sonho da família. As filhas casaram-se uma a uma e todas com rapazes de famílias ligadas à vida rural.

D. Maria, ao ser entrevistada, diz que já realizou parte do sonho, o objetivo de ter uma terra de pelo menos 10 alqueires. Mas que agora, depois de sete anos lá em Eldorado dos Carajás, "pensa de ir para outros lugares porque a terra já está pequena para caber o gadinho que já adquiriu, a terra fica cansada, a água já não é suficiente”. D. Maria planeja com a família ir conhecer e comprar terras lá nas "bandas do Gelado", município de Novo Repartimento, sudeste do Pará. Agora o objetivo é uma terra maior. A filha mais velha casou-se recentemente com um rapaz que tem propriedade rural lá no "Gelado", o genro e a filha estão iniciando a vida, investindo em terra e gado. "Quero uma terra maior. Lá as terras tão bem mais baratas e faz gosto de olhar, ainda tem mata, muita água e as pastagens mesmo em época sem chuva é toda verde, ali sim é terra boa", afirma 
D. Maria. A história de D. Maria e do Sr. Domingos é a história de muitas famílias que expressam ainda não terem conseguido realizar o desejo e os projetos de vida que traçaram quando vieram para a região sul do Pará.Vidas inquietas que se organizam em torno dos planos de espacialização da família em busca de progresso.

Nesse sentido, Guedes afirma sobre a perspectiva nativa que essas diferentes situações apresentam um traço comum: elas são pensadas, segundo o autor, "como formas de andar, rodar, estar no mundo (ou no trecho, dependendo das circunstâncias)" (GUEDES, 2013, p. 31, grifos originais). A recorrência dos temas da mobilidade e dos fluxos migratórios são marcas importantes que caracterizam a cidade de Xinguara. Tanto é uma experiência comum que o próprio morador pioneiro entrevistado se admira diante da lista de lugares por onde já passou:

Já rodei muito pela vida. Nasci no Grajaú, Maranhão, lá desci para Miracema no Tocantins, depois pra Araguaína, Tocantins, vim aqui pro Pará daqui é que não sei mesmo dos lugares que já morei, deixa eu lembrar: um, dois, três, ah! não sei perdi as contas, nunca parei para contar rapaz, é muito lugar andado oh! Vim aqui pros garimpos do tal Cumaru do Norte, aí fui para Santana do Araguaia, peguemos umas derrubadas lá, pra fazer pastos para um fazendeiro, isso meados de 1980. Aí fiquei sabendo que Xinguara tinha ouro, vim pra cá, foi só ilusão, trabalhei muito aí nesses "garimpinhos", mas deu para adquirir uma casa, fiquemos parado por aqui, para ver no que ia dar. Já bati muita cabeça por aí". "Uma hora a gente se assossega", não quero pros meus filhos nem pros meus netos o que eu ja vivi feito doido pelo mundo, de garimpo em garimpo, de roçado em roçado, por isso trabalhei muito e tenho um meio de sobreviver. Hoje são meus filhos que vivem andando por aí. Já disse para eles se sossegarem que o que tem já é bastante, mas parece que "puxaram" para mim, tá no sangue ficar sempre buscando mais jeito de ter uma vida melhor, sei lá..." (J.N.S., 62 anos, reside em Xinguara desde 1980).

A história desse senhor andejo sintetiza a nossa compreensão de pensarmos sobre uma composição de movimentos que inclui, mas que não se limita aos grandes movimentos da migração. A agitação das vidas ordinárias de quem habita Xinguara, cidade cuja avenida principal já foi uma pista de pouso e se sobrepõe com a rodovia PA-279, é o que se destaca nesse contexto.

Apresentamos Xinguara como exemplar dessa dinâmica, sem afirmar sua especificidade; este é tão somente um lugar privilegiado para captar a objetivação de processos ampliados, certamente reencontrados em outros lugares, mas aqui conhecidos de perto pela memória da poeira, dos sons, dos cheiros e dos modos de viver neste nó de caminhos.

\section{Conclusão}

Cidades de qualquer dimensão são "precipitados" da história, como insiste Thomas Bender (2010). Do ponto de vista da pesquisa em cidades, o tempo é tão relevante quanto 
o espaço, pois que "history is not just background or the stage upon which urban life plays out. It is an actant, a participant in the networks" (BENDER, 2010, p. 310). A duração se deixa perceber no curso da vida tal como recontado por moradores que apresentamos, mas essa existência se desenrola por um emaranhado de idas e vindas entre lugares e formas de ganhar a vida que se expande em conexão com gentes, bichos, terra, árvores, águas. Se as conversas recolhidas falavam de movimentos de famílias (MARQUES, 2015) por essa região do Pará, também se povoam de coisas que se plantam e se criam, que se usa para o deslocamento perto e longe; é a memória da cidade nos tempos das vidas de seus moradores, que resulta em uma entidade compósita (BENDER, 2010, p. 304). Alertadas por Bender, podemos apresentar Xinguara abandonando o pressuposto da cidade como totalidade, a partir do qual: "we start with an assumption that the city is some kind of whole, a totality represented as a bounded or at least an identifiable territorial space that gives shape to social relations" (BENDER, 2010, p. 304). Embora haja ali atrás um mapa que situa Xinguara geograficamente, a cartografia que nos interessa apresentar é aquela que surge nos processos de fazer cidade (AGIER, 2015), nos quais as ações de mobilidade são protagonistas.

As histórias que atravessam por Xinguara findam por sugerir que a composição de trajetos individuais e familiares, práticas socioeconômicas e transformações da cidade e seu entorno podem ser vistas como formas da "espacialização da esperança" (PELS, 2015). Esses processos devem ser entendidos no quadro da antropologia do futuro, fundamentalmente atenta ao trabalho do tempo na mutação de sujeitos e espaços. Desde Xinguara, propomos que o estudo das áreas de fronteira, acima de tudo lugares-tempos de movimento, seja inspirado pela pesquisa sobre a "diversity of futures acting on the present" (PELS, 2015, p. 779).

\section{Referências}

AGIER, Michel. Do direito à cidade ao fazer-cidade. O antropólogo, a margem e o centro. Manav, v. 21 n. 3 , p. 483-498, 2015.

ALMEIDA, Alfredo W. B. Movimentos migratórios nos vales do Tapajés e do Xingu. Relatório de pesquisa. Programa de Pós-Graduação em Antropologia Social, Museu Nacional, 1974, mimeografado.

BECKER, Bertha, MIRANDA, Mariana e MACHADO, Lia. Fronteira Amazônica. Questões sobre a gestão do território. Brasília, Editora UnB; Rio de Janeiro: Editora UFRJ, 1990.

BECKER, Berta K. A urbe amazônida: a floresta e a cidade. Rio de Janeiro; Garamond, 2013.

BENDER, Thomas. Postscript: reassembling the city: networks and urban imaginaries. In: Farías, Ignacio e Bender, Thomas (Ed.). Urban Assemblages: how actor-network theory changes urban studies. New York: Routledge, 2010.

DURÃES, Francisco Batista.A pata do boi e a destruição dos ecossistemas locais: história social e memória ambiental de moradores de uma região do sul do Pará. Dissertação (Mestrado em Desenvolvimento Regional e Meio Ambiente) Centro Universitário de Araraquara, Araraquara, 2014.

GUEDES, André Dumans. O trecho, as mães e os papéis. Etnografia de movimentos e durações no norte de Goiás. São Paulo. ANPOCS; Rio de Janeiro: Garamond, 2013. 
GUÉRIOS, Paulo Renato. As condições sociais de produção das lembranças entre imigrantes ucranianos. Mana v.14, n. 2, p. 367-398, 2008.

HÉBETTE, Jean. Cruzando Fronteira. 30 anos de estudo do campesinato na Amazônia. UFPA: Editora UFPA, Belém, 2004. (v. II).

IANNI, O. A luta pela terra: história social da terra e da luta pela terra numa área da Amazônia. Petrópolis:Vozes, 1978.

MARTINS, José de Souza. Fronteira: a degradação do outro nos confins do humano. São Paulo: Contexto, 2012.

A reprodução do capital na frente pioneira e o renascimento da escravidão no Brasil. Tempo Social, v. 6 n. 1-2, p. 1-25, 1994.

MARQUES, Ana Cláudia. Pioneiros de Mato Grosso e Pernambuco: novos e velhos capítulos da colonização no Brasil. Revista Brasileira de Ciências Sociais, v. 28, n. 83, p. 86-103, 2013.

Movimentos em família. Ruris, v. 1, n. 9, p. 13-37, 2015.

MASSEY, Doreen. Pelo Espaço. Uma nova política da espacialidade. Rio de Janeiro: Editora Bertrand Brasil, 2013.

MOURA, Cristina Patriota de. Condomínios e gated communities: por uma antropologia das novas composições urbanas. Anuário Antropológico 2009/II. Rio de Janeiro:Tempo Brasileiro, 2010.

NAIL, Thomas. The figure of the migrant. Stanford: University of California Press, 2015.

OLIVEIRA, João Pacheco de. Uma Etnologia dos “Índios Misturados”? Situação colonial, Territorialização e Fluxos Culturais. Mana, v. 4, n. 1, p. 47-77, 1998.

PELS, Peter. Modern times. Seven steps toward an anthropology of the future. Current Anthropology, v. 56, n. 6, p. 779-796, 2015.

PENNA, Camila. Conexões e controvérsias no INCRA de Marabá. O Estado como um ator heterogêneo. Rio de Janeiro: Garamond, 2015.

PEREIRA, Airton dos Reis. A luta pela terra no sul e sudeste do Pará: migrações, conflitos e violência no campo. 2013. Tese (Doutorado em História) - Universidade Federal de Pernambuco, Recife, 2013.

PEREIRA, José Carlos Matos. A urbanização da Amazônia e os modos de vida na cidade. $37^{\circ}$ ANPOCS, Águas de Lindóia, 2013. POLLAK, Michel. Memória, esquecimento, silêncio. Estudos Históricos, Rio de Janeiro, v. 2, n. 3, p. 3-15, 1989.

RUMSTAIN, Ariana. Peões no trecho: trajetórias e estratégias de mobilidade no Mato Grosso. Rio de Janeiro: E-papers , 2012.

SCHMINK, Marianne; WOOD, Charles H. Conflitos sociais e a formação da Amazônia. Belém: EDUFPA, 2012.

SILVA, Idelma Santiago da. Migração e Cultura no sudeste do Pará: Marabá, (1968-1988). 2006. Dissertação (Mestrado em História) - Universidade Federal de Goiás, Goiânia, 2006.

Fronteira cultural: a alteridade maranhense no

sudeste do Pará (1970-2008). 2010. Tese (Doutorado em História) - Universidade Federal de Goiás, Goiânia, 2010.

SOUZA, Carlos Henrique Lopes. A trajetória da força de trabalho no Sudeste Paraense: de agricultores migrantes a garimpeiros, de garimpeiros a posseiros, a excluídos, a Sem Terra. In: ENCONTRO DA ASSOCIAÇÃO BRASILEIRA DE ESTUDOS POPULACIONAIS, 13., 2002, Ouro Preto. Anais...Ouro Preto, 2002.

VELHO, Otávio Guilherme. Frentes de expansão e estrutura agrária: estudo do processo de penetração numa área da transamazônica. Rio de Janeiro: Zahar, 1972.

Revisitando as frentes de expansão. In:Velho, O.;ALMEIDA,A.W. (Ed.). Revisitando as frentes de expansão. Rio de Janeiro/ São Luís: Casa 8, 2016.

VIEIRA, Maria Antonieta da Costa. À procura das Bandeiras Verdes: viagem, missão e romaria - movimentos sócio-religiosos na Amazônia Oriental. 2001. Tese (Doutorado em Ciências Sociais) - Universidade Estadual de Campinas, Campinas, 2001. 


\section{Migration, mobilities and cities of theAmazon: stories from Xinguara (PA)}

\section{Abstract}

Over the decades, the formation of the cities of Southern Para has been occurring through combinations of economic cycles and population displacements. The article presents the experience of migration of those residents of Xinguara who lived the initial times of the transformation of the city and the region, propitiated by the activities of extraction of wood, gold mining and occupation of lands. It is proposed that mobility in and between the Amazon "border cities" be taken as an expression of a set of values that conceive "walking" as part of life. In this way, we understand that the analysis of urban processes must consider the narratives of lives in tension between flows and stops, border contexts marked by joys and challenges of the unfolding of the new, but also by the destructive violence of certain groups, environment and modes of life.

Keywords: Mobility. Migration. Amazonian cities. Xinguara.

\section{Migración, movilidades y las ciudades de la Amazonia: historias de Xinguara (PA)}

\section{Resumen}

A lo largo de décadas, la formación de las ciudades del sur de Pará viene ocurriendo por combinaciones de ciclos económicos y desplazamientos de población. El artículo presenta la experiencia de migración de aquellos habitantes de Xinguara que vivieron los tiempos iniciales de la transformación de la ciudad y de la región, propiciada por las actividades de extracción de madera, garimpo de oro y ocupación de tierras. Se propone que la movilidad en las "ciudades del borde" amazónicas sea tomada como expresión de un conjunto de valores que conciben la "andanza" como parte de la vida. De este modo, entendemos que el análisis de los procesos urbanos debe considerar las narrativas de vidas en tensión entre flujos y paradas, los contextos de frontera marcados por alegrías y desafios del desbravamiento de lo nuevo, pero también por la violencia destructiva de ciertos grupos, ambiente y modos de vida preexistentes.

Palabras-clave: Movilidad. Migración. Ciudades amazónicas. Xinguara.

Data de recebimento do artigo: 11/02/2019 Data de aprovação do artigo: 11/06/2019 